\title{
Liver chemistry in new-onset Henoch-Schönlein syndrome
}

\author{
Giulia Rosti ${ }^{1 \dagger}$, Gregorio P. Milani ${ }^{2^{*}+}$, Emanuela A. Laicini ${ }^{1}$, Emilio F. Fossali ${ }^{1}$ and Mario G. Bianchetti ${ }^{1,3}$
}

\begin{abstract}
Background: Henoch-Schönlein syndrome is a systemic small-vessel leukocytoclastic vasculitis that usually present with cutaneous, gastrointestinal, articular and renal manifestations. Little is known on liver involvement in this syndrome. This study investigated liver chemistry and creatine kinase in Henoch-Schönlein children.

Case presentation: Alanine aminotransferase, aspartate aminotransferase, $y$-glutamyltransferase, lactate dehydrogenase, total bilirubin, prothrombin time and creatine kinase were assessed in 75 consecutive pediatric patients (41 boys and 34 girls aged from 2.9 to 17 years) with new-onset Henoch-Schönlein syndrome. Mildly altered values were found in 7 (9\%) patients (5 boys and 2 girls aged from 3.3 to 17 years). In the mentioned cases, all tests returned to normal at a 2-4-week follow-up.
\end{abstract}

Conclusions: This preliminary study points out that altered and self-remitting liver parameters occur in approximately $10 \%$ of children with Henoch-Schönlein syndrome.

Keywords: Vasculitis, Allergic purpura, Hepatitis, Elevated liver enzymes, Diagnostic test

\section{Background}

Henoch-Schönlein syndrome, also called immunoglobulin A vasculitis, is the most common systemic vasculitis in childhood [1]. It is a small-vessel leukocytoclastic vasculitis that typically presents with cutaneous, gastrointestinal, articular and renal manifestations [1]. Little is known on liver involvement in this syndrome. Limited data suggest that aminotransferases are elevated in approximately $3 \%$ of children with new-onset HenochSchönlein syndrome and in cases complicated by acalculous cholecystitis or pancreatitis [2, 3]. Exercise, infectious prodromi or drugs with hepatotoxic potential or a pre-existing liver disease, such as non-alcoholic fatty liver disease, might also alter aminotransferases in Henoch-Schönlein syndrome [4, 5]. Herein, we report our prospective single-center experience with liver chemistry and creatine kinase in 75 consecutive pediatric patients affected by this vasculitis syndrome.

\footnotetext{
* Correspondence: milani.gregoriop@gmail.com

${ }^{\dagger}$ Equal contributors

${ }^{2}$ Pediatric unit, Department of Clinical Sciences and Community Health, Università degli Studi di Milano, Fondazione IRCCS Ca' Granda Ospedale Maggiore Policlinico, Via della Commenda 9, 20121 Milan, Italy

Full list of author information is available at the end of the article
}

\section{Study population and methods}

Starting in 2009, at the Pediatric Emergency Unit, Fondazione IRCCS $\mathrm{Ca}^{\prime}$ Granda Ospedale Maggiore Policlinico, Milan, Italy, the initial laboratory approach to new-onset Henoch-Schönlein cases included among others the determination of liver chemistry (alanine aminotransferase, aspartate aminotransferase, $\gamma$-glutamyltransferase, lactate dehydrogenase, total bilirubin and prothrombin time) and creatine kinase in plasma. Urinalysis for hematuria and proteinuria was also assessed.

In subjects with abnormal enzyme levels, plasma amylase was determined and a hepatobiliary ultrasound performed. Finally, the blood tests were repeated approximately $2-4$ weeks later.

The diagnosis of Henoch-Schönlein syndrome was made using the Ankara 2008 - EULAR/PRINTO/PRES criteria [6]. The CAAR grading system for cutaneous, abdominal, articular, and renal involvement was applied to assess the systemic disease activity [7].

From each case, we collected data on ethnicity, preexisting chronic conditions, possible triggers (defined as acute illness or vaccination $[1,8]$ preceding the skin lesions by $\leq 14$ days) and repetitive exercise $\leq 3$ days before admission to the emergency department. A careful drug 
history, including both prescribed and over-the-counter medications, was also taken.

The liver and spleen borders were estimated clinically at the end of inspiration: the liver border was determined by percussion and palpation in the right midclavicular line and the diagnosis of hepatomegaly was made when the liver edge projected $>2 \mathrm{~cm}$ below the margin [9]; the spleen border was determined by palpation in the left anterior axillary line and the diagnosis of splenomegaly was made when the spleen was palpable [10]. Finally, the Murphy sign was considered positive in cases with pain on inspiration while palpating the right upper abdominal quadrant.

A kinetic assay was used for alanine aminotransferase (reference: $<50 \mathrm{U} / \mathrm{L}$ ), aspartate amintransferase (reference: $<50 \mathrm{U} / \mathrm{L}$ ) and amylase (reference: $<120 \mathrm{U} / \mathrm{L}$ ), an ultraviolet spectrophotometry for lactate dehydrogenase (reference: $<500 \mathrm{U} / \mathrm{L}$ ) and creatine kinase (reference: $<150 \mathrm{U} / \mathrm{L}$ ), a kinetic colorimetry for $\gamma$-glutamyltransferase (reference: $<50 \mathrm{U} / \mathrm{L}$ ), a diazo colorimetry for total bilirubin (reference: $<20 \mu \mathrm{mol} / \mathrm{L}$ ) and an automated clotting assay for prothrombin time (reference: 0.90-1.30 INR). An automated dipstick system was used for hematuria and proteinuria.

Enzyme values were graded as normal or mildly $(<5$ times the upper reference limit), moderately (5-10 times) and markedly ( $>10$ times) altered. Data analysis was approved of by the Ethical Committee of our hospital. Anonymized patient information was used for data analysis. Data are given either as median and interquartile range or as relative frequency. The one-sample Mann-Whitney-Wilcoxon test was used to compare the results with those of the general population. Significance was assumed when $P<0.05$.

\section{Case presentation}

Between January 2009 and June 2016, we made the diagnosis of new-onset Henoch-Schönlein syndrome in 72 Caucasian and 3 Hispanic patients up to 17 years of age presented to the Pediatric Emergency Unit. History, clinical findings and renal involvement are given in Table 1. A possible trigger, either an infection or a vaccination, was reported by 49 (65\%) patients. Forty-one $(55 \%)$ cases had been managed with paracetamol, a nonsteroidal anti-inflammatory drug, a penicillin or a macrolide.

The results of liver chemistry and creatine kinase appear in Fig. 1. As compared with the general population, blood values were not abnormally elevated in HenochSchönlein patients.

Enzyme levels were normal in 68 and mildly elevated in the remaining 7 patients. None of them presented with hepatomegaly, splenomegaly or Murphy sign. Circulating amylase and hepatobiliary ultrasound were found to be normal in these cases.
Table 1 History, clinical findings and renal involvement in 75 pediatric patients aged from 2.9 to 17 years with new-onset Henoch-Schönlein syndrome. Data are given either as relative frequency or as median and interquartile range

\begin{tabular}{|c|c|}
\hline Age, years & $6.4[4.8-7.7]$ \\
\hline Gender, 0 : & $41: 34$ \\
\hline Pre-existing chronic condition, $\mathrm{N}$ & 0 \\
\hline Recent repetitive exercise & 5 \\
\hline \multicolumn{2}{|l|}{ Triggers } \\
\hline Acute lower respiratory infection, $\mathrm{N}$ & 15 \\
\hline Acute upper respiratory infection, $\mathrm{N}$ & 14 \\
\hline Nonspecific febrile illness, N & 10 \\
\hline Urinary tract infection, $\mathrm{N}$ & 6 \\
\hline Acute diarrheal disease, $\mathrm{N}$ & 3 \\
\hline Vaccination, N & 1 \\
\hline \multicolumn{2}{|l|}{ Drug management } \\
\hline Paracetamol, N & 31 \\
\hline Nonsteroidal anti-inflammatories, $\mathrm{N}$ & 12 \\
\hline Penicillins, $N$ & 15 \\
\hline Macrolides, N & 4 \\
\hline \multicolumn{2}{|l|}{ Clinical findings } \\
\hline Hepatomegaly, N & 2 \\
\hline Splenomegaly, N & 1 \\
\hline Hepatosplenomegaly, N & 1 \\
\hline Murphy sign, N & 0 \\
\hline \multicolumn{2}{|l|}{ Cutaneous involvement } \\
\hline Mild, N & 47 \\
\hline Moderate, $\mathrm{N}$ & 25 \\
\hline Severe, N & 3 \\
\hline \multicolumn{2}{|l|}{ Abdominal involvement } \\
\hline None, N & 28 \\
\hline Mild, N & 28 \\
\hline Moderate, $\mathrm{N}$ & 17 \\
\hline Severe, N & 2 \\
\hline \multicolumn{2}{|l|}{ Articular involvement } \\
\hline None, N & 14 \\
\hline Mild, N & 46 \\
\hline Moderate, N & 12 \\
\hline Severe, N & 3 \\
\hline \multicolumn{2}{|l|}{ Renal involvement } \\
\hline None, N & 45 \\
\hline Mild, N & 22 \\
\hline Moderate, N & 7 \\
\hline Severe, N & 1 \\
\hline
\end{tabular}



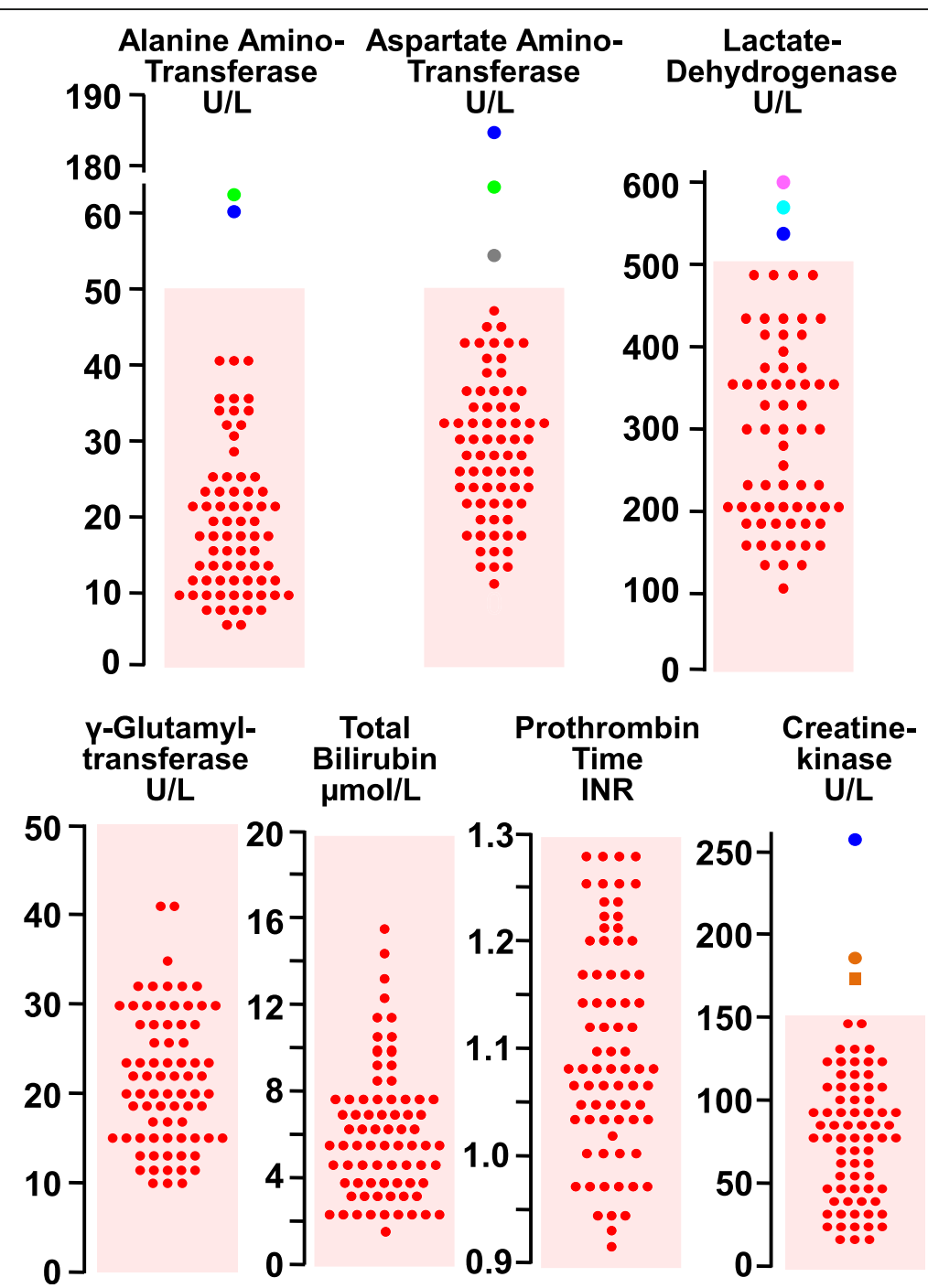

Fig. 1 Liver parameters in 75 consecutive children with new-onset Henoch-Schönlein syndrome. An isolated increase in creatine kinase was observed in two boys 7.5 and 9.3 years of age, respectively [orange circle; orange square]. Altered liver parameters were also noted in five subjects: a 5.4-year-old Caucasian male [blue circle], a 6.7-year-old Caucasian male [green circle], a 17-year-old Hispanic female [gray circle], a 6.2-year-old Caucasian male [lavender circle], and a 3.3-year-old Caucasian girl [aqua circle]

An isolated increase in creatine kinase $(175$ and $189 \mathrm{U} / \mathrm{L}$, respectively) was observed in two boys (7.5 and 9.3 years of age, respectively) with recent history of repetitive exercise. An increase in plasma creatine kinase $(265 \mathrm{U} / \mathrm{L})$, associated with elevated alanine aminotransferase $(60 \mathrm{U} / \mathrm{L})$, aspartate aminotransferase $(186 \mathrm{U} / \mathrm{L})$ and lactate dehydrogenase $(523 \mathrm{U} / \mathrm{L})$ was also observed in a 5.4-year-old boy with recent extended physical activity.

An altered liver chemistry was noted in further four patients: a 6.7-year-old Caucasian male (alanine aminotransferase $64 \mathrm{U} / \mathrm{L}$, aspartate aminotransferase $65 \mathrm{U} / \mathrm{L}$ ); a 17-year-old Hispanic female (aspartate aminotransferase $53 \mathrm{U} / \mathrm{L}$ ); a 6.2-year-old Caucasian male (lactate dehydrogenase $603 \mathrm{U} / \mathrm{L}$ ); and a 3.3-year-old Caucasian girl (lactate dehydrogenase level 540 U/L). Henoch-Schönlein syndrome had been preceded by an upper $(N=2)$ or a lower $(N=2)$ respiratory tract infection in these four patients and treatment with paracetamol $40-60 \mathrm{mg} / \mathrm{kg}$ body weight daily had been recommended for fever, abdominal pain or arthralgia.

At the 4-week follow-up, the parameters were normal in the 7 patients with altered tests.

\section{Discussion}

This is the first prospective study investigating liver chemistry and creatine kinase in unselected HenochSchönlein children. These tests are normal at presentation in about $90 \%$ and mildly elevated in $10 \%$ of these patients. In the latter cases, liver parameters are transiently altered and self-remit within 4 weeks. Similar 
observations were recently made in patients affected with acute hemorrhagic edema of young children, the infantile variant of Henoch-Schönlein syndrome [11].

Exercise likely accounts for the altered tests observed in 3 patients with recent history of extended physical activity $[4,5]$. On the contrary, we do not have a clear-cut explanation for the transiently altered liver chemistry noted in the remaining 4 cases. We speculate that altered liver tests resulted either from the infectious prodrome or from unreported self-administration of a drug with hepatotoxic potential. Finally, the strategy used to establish cut off values implies that a result out of range is not necessarily pathologic and is found in $2-3 \%$ of healthy subjects.

The findings of this study confirm those of a retrospective analysis including apparently unselected HenochSchönlein children from the Republic of China [12]. In that report, mildly elevated alanine aminotransferase levels were observed in $9 \%$ of the cases. However, creatine kinase levels were not assessed in those children.

Some months after starting the investigation presented in this report, the use of lower laboratory thresholds for alanine aminotranferase (i.e. $25 \mathrm{U} / \mathrm{L}$ instead of $50 \mathrm{U} / \mathrm{L}$ ) was proposed for children affected by a chronic liver disease [13]. This recommendation deserves in our opinion further support.

The main limitations of this preliminary study were its single center design, the rather small sample size and the ethnic homogeneity of the study population.

\section{Conclusions}

This preliminary study points out that altered and selfremitting liver chemistry or creatine kinase are found in approximately $10 \%$ of children with Henoch-Schönlein syndrome.

\section{Acknowledgements}

The authors would like to thank Dr. Alec Villa for his assistance in the linguistic revision.

\section{Funding}

None.

\section{Availability of data and materials}

The datasets used and/or analyzed during the current study are available from the last author on reasonable request.

\footnotetext{
Authors' contributions

GR, GPM, EFF, MGB conceptualized the study. GR and EAL conducted the study and collected data. GR, MGB and EFF performed statistical analysis and interpreted the results. GPM and EAL gave a significant contribution on their field of expertise. GPM and MGB wrote the first draft of the manuscript. EEF supervised the whole study. All authors critically reviewed the first draft, approved the final manuscript as submitted and take full responsibility for the manuscript.
}

Ethics approval and consent to participate

The study was approved by the local ethical committee.

\section{Competing interests}

The authors declare that they have no competing interests.

\section{Publisher's Note}

Springer Nature remains neutral with regard to jurisdictional claims in published maps and institutional affiliations.

\section{Author details}

1Pediatric Emergency Unit, Fondazione IRCCS Ca' Granda Ospedale Maggiore Policlinico, Milan, Italy. ${ }^{2}$ Pediatric unit, Department of Clinical Sciences and Community Health, Università degli Studi di Milano, Fondazione IRCCS Ca' Granda Ospedale Maggiore Policlinico, Via della Commenda 9, 20121 Milan, Italy. ${ }^{3}$ Pediatric Department of Southern Switzerland, Bellinzona, Switzerland.

Received: 1 May 2017 Accepted: 13 September 2017

Published online: 21 September 2017

\section{References}

1. Lava SAG, Milani GP, Fossali EF, Simonetti GD, Agostoni C, Bianchetti MG. Cutaneous manifestations of small-vessel leukocytoclastic vasculitides in childhood. Clin Rev Allergy Immunol. 2017; doi:10.1007/s12016-017-8626-3.

2. Trapani S, Micheli A, Grisolia F, Resti M, Chiappini E, Falcini F, De Martino M. Henoch Schonlein purpura in childhood: epidemiological and clinical analysis of 150 cases over a 5-year period and review of literature. Semin Arthritis Rheum. 2005;35:143-53.

3. Helbling R, Lava SA, Simonetti GD, Camozzi P, Bianchetti MG, Milani GP. Gallbladder and pancreas in Henoch-Schönlein purpura: review of the literature. J Pediatr Gastroenterol Nutr. 2016;62:457-61.

4. Lee TH, Kim WR, Poterucha JJ. Evaluation of elevated liver enzymes. Clin Liver Dis. 2012;16:183-98.

5. Gualco G, Lava SA, Garzoni L, Simonetti GD, Bettinelli A, Milani GP, Provero MC, Bianchetti MG. Transient benign hyperphophatasemia. I Pediatr Gastroenterol Nutr. 2013:57:167-71.

6. Ruperto N, Ozen S, Pistorio A, Dolezalova P, Brogan P, Cabral DA, Cuttica R, Khubchandani R, Lovell DJ, O'Neil KM, Quartier P, Ravelli A, Iusan SM, Filocamo G, Magalhães CS, Unsal E, Oliveira S, Bracaglia C, Bagga A, Stanevicha V, Manzoni SM, Pratsidou P, Lepore L, Espada G, Kone-Paut I, Zulian F, Barone P, Bircan Z, Maldonado Mdel R, Russo R, Vilca I, Tullus K, Cimaz R, Horneff G, Anton J, Garay S, Nielsen S, Barbano G, Martini A, Paediatric Rheumatology International Trials Organisation. EULAR/PRINTO/ PRES criteria for Henoch-Schönlein purpura, childhood polyarteritis nodosa, childhood Wegener granulomatosis and childhood Takayasu arteritis: Ankara 2008. Part I: Overall methodology and clinical characterisation. Ann Rheum Dis. 2010:69:790-7.

7. Ramelli V, Lava SA, Simonetti GD, Bianchetti MG, Ramelli GP, Milani GP. Blistering eruptions in childhood Henoch-Schönlein syndrome: systematic review of the literature. Eur J Pediatr. 2017;176:487-92.

8. Da Dalt L, Zerbinati C, Strafella MS, Renna S, Riceputi L, Di Pietro P, Barabino P, Scanferla S, Raucci U, Mores N, Compagnone A, Da Cas R, Menniti-Ippolito F, Italian Multicenter Study Group for Drug and Vaccine Safety in Children. Henoch-Schönlein purpura and drug and vaccine use in childhood: a casecontrol study. Ital J Pediatr. 2016;42:60

9. Deligeorgis D, Yannakos D, Panayotou P, Doxiadis S. The normal borders of the liver in infancy and childhood. Clinical and x-ray study. Arch Dis Child. 1970:45:702-4.

10. Sullivan S, Williams R. Reliability of clinical techniques for detecting splenic enlargement. Br Med J. 1976;273:1043-4.

11. Ferrarini A, Benetti C, Camozzi P, Ostini A, Simonetti GD, Milani GP, Bianchetti MG, Lava SAG. Acute hemorrhagic edema of young children: a prospective case series. Eur J Pediatr. 2016;175:557-61.

12. Chao HC, Kong MS, Lin SJ. Hepatobiliary involvement of Henoch-Schönlein purpura in children. Acta Paediatr Taiwan. 2000;41:63-8.

13. Schwimmer JB, Dunn W, Norman GJ, Pardee PE, Middleton MS, Kerkar N, Sirlin CB. SAFETY study: alanine aminotransferase cutoff values are set too high for reliable detection of pediatric chronic liver disease. Gastroenterology. 2010;138:1357-64. 